Cochrane Database of Systematic Reviews

\title{
Tocilizumab for thyroid eye disease (Review)
}

Hamed Azzam S, Kang S, Salvi M, Ezra DG

Hamed Azzam S, Kang S, Salvi M, Ezra DG.

Tocilizumab for thyroid eye disease.

Cochrane Database of Systematic Reviews 2018, Issue 11. Art. No.: CD012984.

DOI: 10.1002/14651858.CD012984.pub2.

www.cochranelibrary.com 
HEADER 1

ABSTRACT

PLAIN LANGUAGE SUMMARY

BACKGROUND

OBJECTIVES

METHODS

RESULTS

Figure 1.

DISCUSSION

AUTHORS' CONCLUSIONS

ACKNOWLEDGEMENTS

REFERENCES

CHARACTERISTICS OF STUDIES

ADDITIONAL TABLES

APPENDICES

CONTRIBUTIONS OF AUTHORS

DECLARATIONS OF INTEREST

SOURCES OF SUPPORT

INDEX TERMS

\section{TABLE OF CONTENTS}


[Intervention Review]

\section{Tocilizumab for thyroid eye disease}

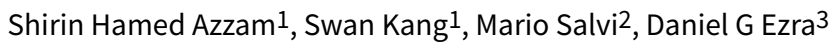

1Moorfields Eye Hospital NHS Foundation Trust, London, UK. ${ }^{2}$ Milan, Italy. ${ }^{3}$ Moorfields and UCL Institute of Ophthalmology BMRC, Moorfields Eye Hospital NHS Foundation Trust, London, UK

Contact address: Shirin Hamed Azzam, Moorfields Eye Hospital NHS Foundation Trust, 162 City Road, London, EC1V 2PD, UK. shirinhamedazzam@gmail.com.

Editorial group: Cochrane Eyes and Vision Group.

Publication status and date: New, published in Issue 11, 2018.

Citation: Hamed Azzam S, Kang S, Salvi M, Ezra DG. Tocilizumab for thyroid eye disease. Cochrane Database of Systematic Reviews 2018, Issue 11. Art. No.: CD012984. DOI: 10.1002/14651858.CD012984.pub2.

Copyright (c) 2018 The Cochrane Collaboration. Published by John Wiley \& Sons, Ltd.

\section{A B S T R A C T}

\section{Background}

Thyroid eye disease (TED) is an autoimmune disorder that constitutes a major clinical and therapeutic challenge. Current treatment options for moderate-to-severe TED include immunotherapy, orbital radiotherapy and decompression surgery. Limited drugs of proven efficacy are available for the treatment of people with TED. Given the role in the pathogenesis of TED of interleukin (IL)- 6 expression in adipocytes, fibroblasts and macrophages, the proposed theory is that inhibition of IL- 6 by tocilizumab may be an effective treatment in TED by directly reducing the inflammatory response. In addition, there is an unmet need for a new treatment that can modify the natural course of the disease and reduce the incidence of late complications that can occur as a result of fibrosis following inflammation.

\section{Objectives}

To investigate the efficacy and harms of tocilizumab for the treatment of people with TED.

\section{Search methods}

We searched the Cochrane Central Register of Controlled Trials (CENTRAL) (which contains the Cochrane Eyes and Vision Trials Register) (2018, Issue 6); MEDLINE Ovid; Embase Ovid; LILACS BIREME; OpenGrey; the ISRCTN registry; ClinicalTrials.gov; the World Health Organization (WHO) International Clinical Trials Registry Platform (ICTRP) and the EU Clinical Trials Register. The date of the search was 31 July 2018.

\section{Selection criteria}

We searched for trials of tocilizumab administered by intravenous infusion using any dosage regimen, compared with placebo or intravenous glucocorticoid therapy for people with TED.

\section{Data collection and analysis}

We planned to use standard methods recommended by Cochrane. The primary outcome was change in TED score (as defined by investigators). Secondary outcomes included measurement of the following parameters: change in proptosis, change in extraocular motility, change in palpebral aperture measurements, number of relapses, development of optic neuropathy and change in quality of life score. We planned to measure these outcomes at three months (range two to six months) and 12 months (range six to 18 months) posttreatment. Adverse outcomes included any adverse effects identified in the trials at any time point.

\section{Main results}

No studies met the inclusion criteria of this review. We found one randomised, placebo-controlled, double masked study (NCT01297699). This study plans to evaluate the efficacy and harms of tocilizumab administration in people with moderate-to-severe or sight-threatening 
graves' ophthalmopathy (GO), that had not responded adequately to treatment with intravenous corticosteroid pulses. It was completed in December 2015 and will be assessed for inclusion in the review when data become available.

\section{Authors' conclusions}

There is currently no evidence from randomised controlled trials evaluating the efficacy and harms of tocilizumab for the treatment of people with TED.

\section{PLAIN LANGUAGE SUMMARY}

\section{Tocilizumab for thyroid eye disease}

\section{What was the aim of this review?}

The aim of this review was to find out if tocilizumab is helpful for the treatment of thyroid eye disease (TED). Cochrane researchers searched for studies to answer this question and found no relevant studies.

\section{Key messages}

At present, there is no evidence from well-designed studies to show that tocilizumab works, and has no side effects, for people with TED.

\section{What was studied in this review?}

TED is a common condition. TED is an autoimmune disease which means that a person's own immune system attacks and damages the eye and eye socket (orbit). Current treatments for TED include glucocorticosteroids, radiation and surgery. These treatments may have significant undesirable side effects. Tocilizumab is a drug that suppresses the immune system. It is used to treat other autoimmune diseases such as rheumatoid arthritis and systemic juvenile idiopathic arthritis. Tocilizumab has been used to treat people with TED and there are reports that it works.

\section{What are the main results of the review?}

The Cochrane researchers found no completed studies that met the standard to be included in this review.

\section{How up-to-date is this review?}

The Cochrane researchers searched for studies published up to 31 July 2018. 


\section{B A C K G R O U N D}

\section{Description of the condition}

Thyroid eye disease (TED) is an autoimmune disorder that constitutes a major clinical and therapeutic challenge. TED occurs in up to $50 \%$ of people with Graves' disease; however, it may also occur without current or prior hyperthyroidism, or in people who are hypothyroid due to chronic autoimmune (Hashimoto's) thyroiditis (Bartalena 2008). Graves' disease affects approximately $1 \%$ to $2 \%$ of adults (Weetman 2000), and approximately $20 \%$ to $25 \%$ of people with Graves' hyperthyroidism have clinically apparent TED at the time of diagnosis (Burch 1993; Minakaran 2013). Reported incidence rates are $16 / 100,000$ for women and $2.9 / 100,000$ for men, and calculated prevalence is $0.25 \%$ (Bartley 1995).

The pathophysiology of TED is still not completely understood. Stimulation of inflammatory cytokines causes proliferation of the orbital fibroblasts, which in turn produce collagen and glycosaminoglycans in the extracellular matrix (Prabhakar 2003; Wiersinga 2001). The polyanionic charge and the high osmotic pressure of this matrix substance cause swelling of the extraocular muscles (Wiersinga 2001). In addition, a subgroup of orbital fibroblasts can differentiate into new mature fat cells (adipogenesis), which cause increased orbital tissue volume (Sorisky 1996). There is also a role for the humoralmediated immune response (Han 2006), in which thyrotropin receptor autoantibodies and immunoglobulins targeting insulinlike growth factor- 1 receptors contribute to fibroblast activation and glycosaminoglycan secretion (Eckstein 2009; Ezra 2012).

The symptoms of TED may range from sore, gritty and red eyes to double vision, or reduced or loss of vision. The common clinical signs of TED include lid retraction and proptosis. Levator and Muller muscle inflammation and fibrosis can cause upper eyelid retraction, which is seen in up to $90 \%$ of affected people (Bahn 2010). Proptosis is caused by the expansion of orbital fat (type 1 orbitopathy), extraocular muscles (type 2 orbitopathy), or both (Hiromatsu 2000). TED even in its mild form has a deleterious effect on quality of life (Wickwar 2015), and in its severe form can lead to visual loss in 3\% to $7 \%$ of affected people secondary to compressive optic neuropathy or exposure keratopathy (Bahn 2010; Barrio-Barrio 2015; Kahaly 2005).

The clinical manifestation of TED can be assessed using several classification systems. The NO SPECS (No physical signs or symptoms, Only signs, Soft tissue involvement, Proptosis, Extraocular muscle involvement, Corneal involvement, and Sight loss (due to optic nerve involvement)) classification was first reported by Werner in 1969 (Werner 1969). Later, Werner published the modified NO SPECS classification and this has been widely used since (Werner 1977). The NO SPECS classification does not differentiate between inflammatory progressive and noninflammatory status, but grades clinical severity. Mourits and colleagues later described the Clinical Activity Score (CAS) classification, which differentiates between the active and quiescent stages of the disease and is based on the classic signs of acute inflammation (pain, swelling, redness and impaired function) (Mourits 1989). The modification in 1997 included 10points that requires two consecutive clinical examinations as three of these items are scored based on the change in clinical signs (Mourits 1997). Active ophthalmopathy is defined as the score of $3 / 7$ or greater at the first examination, or g4/10 or greater on successive examination. Later in 2006, European Group On Graves' Orbitopathy (EUGOGO) proposed a modification of this classification in which the clinical score can be obtained after a single clinical examination. This modified system has a total score of 7 and does not include an evaluation of change in visual acuity, diplopia or proptosis (EUGOGO 2006). Currently, the VISA (Vision, Inflammation, Strabismus, and Appearance) classification is widely used in the USA and North America, whereas the EUGOGO classification is used in Europe (Barrio-Barrio 2015). Both these classifications assess the signs of activity and the degree of severity of the disease. As with the classification systems available, the treatment options vary: EUGOGO guidelines emphasise the use of intravenous corticosteroid (IV CS) as the superior treatment (Bartalena 2016), whereas the American Thyroid Association (2011) recommend treating the hyperthyroidism rather than the TED itself (Bahn 2011).

Smoking and unstable thyroid function levels are risk factors for TED. Smoking, even the history of smoking, is an independent risk factor associated with an impaired response to TED treatments such as IV CS (Xing 2015). In addition, radioiodine therapy is a significant risk factor for the development or worsening of TED; worsening of the condition can be prevented using prophylactic glucocorticoids in people with pre-existing TED (Li 2016).

People with TED usually receive advice on lifestyle modification, such as smoking cessation (Thornton 2007), together with a variety of medical and surgical treatment modalities ranging from immunosuppression with glucocorticoids (Kahaly 2005) to focal radiotherapy (Bartalena 2002) to surgical decompression (Kingdom 2015). Somatostatin analogues and immunomodulators, such as ciclosporin, have been trialled with limited success (Yang 2011). Oral glucocorticoid therapy tapered over 10 to 24 weeks is used frequently, although parenteral steroid administration appears to be superior in efficacy with improved quality of life (Stan 2012). One systematic review of the effectiveness of orbital irradiation found that treatment with a combination of radiotherapy and steroids is superior to steroid monotherapy (Rajendram 2008). Surgical interventions include orbital decompression, strabismus surgery and eyelid surgery. Surgical decompression is usually reserved for people with significant proptosis and sight-threatening exposure keratopathy or compressive optic neuropathy (or both). Several surgical techniques have been used for orbital decompression and the endonasal approach appears to have a low complication rate (Boboridis 2015).

\section{Description of the intervention}

Tocilizumab is a recombinant humanised antihuman monoclonal antibody of the immunoglobulin $\mathrm{G} 1$ subclass directed against the interleukin- 6 receptor (IL-6R), produced by recombinant DNA technology (Perez-Moreiras 2014). Tocilizumab specifically binds to IL-6R, both the soluble and membrane-bound forms (IL-6RM). Interleukin (IL)- 6 inhibits both IL-6RM and IL-6-mediated transsignalling through IL-6R. Tocilizumab is sold under trade names such as Actemra and RoActemra and is approved by the European Medicines Agency and US Food and Drug Administration for the treatment of people with active moderate-to-severe rheumatoid arthritis that is unresponsive to standard therapies (Firestein 2003; Rose-John 2007; Smolen 2003). It is administered intravenously at a dose of $4 \mathrm{mg} / \mathrm{kg}$ to $8 \mathrm{mg} / \mathrm{kg}$ every four weeks. Many largescale global studies have demonstrated the efficacy and safety of 
tocilizumab for the treatment of people with rheumatoid arthritis, and in April 2008 the drug was first approved in Japan for this indication (Kaneko 2013).

\section{How the intervention might work}

There are several proposed theories as to how tocilizumab may work in TED. IL-6 is a proinflammatory cytokine produced by various cell types, including $T$ and $B$ lymphocytes, monocytes and fibroblasts (Jyonouchi 2001; Lehmann 2008). IL-6 is involved in various physiological processes, such as T-cell activation, induction of immunoglobulin secretion, induction of the hepatic synthesis of acute-phase proteins and the stimulation of haemotopoiesis. IL-6 is present in high concentrations in people with TED and plays an important role in the pathogenesis of the disease, as previous in vitro and ex vivo experiments have shown (Anvari 2010; Hiromatsu 2000; Slowik 2012). Immune cells such as B and T lymphocytes play an important role in the early stages of TED. Further disease progression is postulated to involve the recruitment of $T$ cells into the orbit to engage in reciprocal immune activation and amplify $B$-cell responses, resulting in inflammatory processes such as the production of cytokines (including IL-6) and prostaglandins that lead to the tissue expansion and remodelling that is characteristic of the orbital soft tissue expansion seen in TED (Lehmann 2008).

However, in addition to an immunomodulatory function, there is evidence that IL- 6 targeting may also affect mesenchymal cells, which could alter extracellular matrix remodelling. Studies have shown that IL- 6 increases the expression of the thyrotropin receptor in orbital preadipocytes (Bahn 1993; Jyonouchi 2001; Natt 1997). Furthermore, high levels of IL-6 produced by differentiated adipocytes and fibroblasts stimulate $B$ lymphocytes and produce thyroid-stimulating immunoglobulin (TSI). Fibroblasts present in the orbit, when activated by TSI and tumour growth factor-beta, may differentiate into myofibroblasts or adipocytes, leading to glycosaminoglycan production, adipogenesis and inflammation or fibrosis (Prabhakar 2003; Smith 1997). Reducing the effect of IL-6 by blocking its receptors may play a role in lowering TSI blood levels, and in improving proptosis and extraocular motility.

Given the role in TED of IL-6 expression in adipocytes (Jyonouchi 2001), fibroblasts and macrophages, and the existing experience of the use of different biological therapies, the proposed theory is that inhibition of IL- 6 may be an effective treatment in TED by directly reducing the inflammatory response and fibroblast activity, and hence altering extracellular matrix remodelling.

\section{Why it is important to do this review}

TED is the most common extrathyroidal manifestation of Graves' disease and, in its severe form, it can cause visual loss. Current treatment options for moderate-to-severe TED include immunotherapy (mainly glucocorticosteroids), orbital radiotherapy (Rajendram 2012), and decompression surgery (Boboridis 2011). Limited drugs of proven efficacy are available for the treatment of people with TED. The adverse effect profiles of the currently available treatments are undesirable, especially those of the most commonly used first-line agents - glucocorticosteroids which are associated with adverse effects such as diabetes mellitus, hypertension, acute heart failure, weight gain, osteoporosis and acute liver failure.
In addition, there is an unmet need for a new treatment that can modify the natural course of the disease and reduce the incidence of late complications that can occur as a result of fibrosis following inflammation. Tocilizumab is a biological agent that has been used successfully in other autoimmune conditions including rheumatoid arthritis. Some studies have demonstrated the efficacy of tocilizumab in the treatment of people with active moderateto-severe TED, but there are no clear guidelines regarding its use (Perez-Moreiras 2014; Sy 2017). Therefore, it is important to systematically review all the current evidence in order to draw conclusions on the use of tocilizumab in the management of TED.

\section{O B JECT IVES}

To investigate the efficacy and harms of tocilizumab for the treatment of people with TED.

\section{METHODS}

\section{Criteria for considering studies for this review}

\section{Types of studies}

We planned to include randomised controlled trials (RCTs) that investigated the use of tocilizumab in the treatment of people with TED.

\section{Types of participants}

Trials involving adults (aged 18 years and over) with active TED (CAS 3 or greater at baseline, 4 or greater at subsequent visits).

\section{Types of interventions}

We planned to include trials of tocilizumab administered by intravenous infusion using any dosage regimen, compared with placebo or intravenous glucocorticoid therapy.

\section{Types of outcome measures}

\section{Primary outcomes}

- Change in TED as defined by investigators, at three months (range two to six months) and 12 months (range six to 18 months) post treatment. This may include classification scores such as CAS, EUGOGO, NOSPECS and VISA.

\section{Secondary outcomes}

The secondary outcomes for this review were the following at three months (range two to six months) and 12 months (range six to 18 months) post treatment.

- Change in proptosis (measured in millimetres) (if change in proptosis was not reported and only one time-point measurement of proptosis was reported then we collected the final values).

- Change in extraocular motility (measured in degrees) (if change in extraocular motility was not reported and only one timepoint measurement of extraocular motility was reported then we collected the final values).

- Change in palpebral aperture measurements (measured in millimetre) (if change in palpebral aperture measurements was not reported and only one time-point measurement of palpebral aperture was reported then we collected the final values).

- Number of relapses (per participant). 
- Development of optic neuropathy (as defined by the trial investigators).

- Change in quality of life score: we used any validated measure, for example Graves' Orbitopathy Quality of Life Questionnaire (GO-QOL) score or EuroQol EQ-5D score.

\section{Adverse effects}

- Adverse effects identified in the included trials.

\section{Search methods for identification of studies}

\section{Electronic searches}

The Cochrane Eyes and Vision Information Specialist searched the following electronic databases for RCTs and controlled clinical trials. We imposed no language or publication year restrictions.

- Cochrane Central Register of Controlled Trials (CENTRAL) (which contains the Cochrane Eyes and Vision Trials Register) in the Cochrane Library (searched 31 July 2018) (Appendix 1).

- MEDLINE Ovid (1946 to 31 July 2018) (Appendix 2)

- Embase Ovid (1980 to 31 July 2018) (Appendix 3).

- LILACS BIREME (Latin American and Caribbean Health Science Information Database) (1982 to 31 July 2018) (Appendix 4).

- OpenGrey (opengrey.eu/: searched 31 July 2018) (Appendix 5).

- ISRCTN registry (www.isrctn.com/editAdvancedSearch; searched 31 July 2018) (Appendix 6).

- US National Institutes of Health Ongoing Trials Register ClinicalTrials.gov (www.clinicaltrials.gov; searched 31 July 2018) (Appendix 7).

- World Health Organization (WHO) International Clinical Trials Registry Platform (ICTRP) (www.who.int/ictrp; searched 31 July 2018) (Appendix 8).

- EU Clinical Trials Register (clinicaltrialsregister.eu: searched 31 July 2018) (Appendix 9).

\section{Searching other resources}

We manually searched the reference lists of review articles and used the Science Citation Index to identify additional studies citing trials. We contacted the lead investigators of relevant trials on ClinicalTrials.gov and the WHO ICTRP for information and data from as yet unpublished clinical trials. We contacted experts in the field for information about any ongoing trials. We contacted the manufacturers of tocilizumab for details of any sponsored trials.

\section{Data collection and analysis}

\section{Selection of studies}

Using Covidence (Covidence), two review authors independently inspected the titles and abstracts resulting from the electronic and manual searches and classified each abstract as relevant, potentially relevant or not relevant for this review. We obtained full-text copies of articles identified as relevant or potentially relevant. Two review authors independently assessed each article and applied the inclusion criteria to determine final eligibility. We resolved discrepancies through discussion and consensus. We documented the excluded studies and reasons for exclusion.

\section{Data extraction and management}

Two review authors planned to independently extract data using a prepiloted online form and the web-based software Covidence to screen the citation, review full-texts, perform 'Risk of bias' assessments, and extract study characteristics and outcomes. One review author planned to import data from Covidence into Review Manager 5 (RevMan 5) (Review Manager 2014), and a second review author planned to check the entered data for errors or inconsistencies.

\section{Assessment of risk of bias in included studies}

Two review authors planned to assess the methodological quality of the selected trials according to the methods set out in Chapter 8 of the Cochrane Handbook for Systematic Reviews of Intervention (Higgins 2017). We planned to consider the following six parameters when assessing the risk of bias.

- Random sequence generation (selection bias).

- Allocation concealment (selection bias).

- Blinding (masking) of participants and outcome assessors (performance bias and detection bias).

- Incomplete outcome data (attrition bias).

- Selective outcome reporting (reporting bias).

- Other sources of bias.

We planned to assess each parameter for low risk of bias, high risk of bias or unclear risk of bias. We planned to contact the authors of trials for additional information on domains we judged to be at unclear risk of bias. We planned to resolve discrepancies between review authors by discussion and consensus.

\section{Measures of treatment effect}

We planned to report continuous variables where the data were normally distributed as means and standard deviations (SD), and where the data were not normally distributed as medians and interquartile ranges (IQR). Medians and IQRs were not planned to be meta-analysed. Anticipated variables included changes in thyroidassociated CAS, proptosis, palpebral aperture measurements, extraocular motility and quality of life scores. If there were more than two studies and they used different measurement scales to assess the same outcome across the included studies, we intended to use the standardised mean difference (SMD). We planned to report dichotomous variables as risk ratios (RR) with 95\% confidence intervals $(\mathrm{Cl})$. Such variables would include the proportion of participants experiencing each adverse effect.

\section{Unit of analysis issues}

The treatment is a systemic treatment and therefore would be expected to affect both eyes of each participant. Included studies would randomise participants rather than eyes. The CAS score is calculated for each participant and so the unit of analysis for these data would be the participant. For proptosis, palpebral aperture and extraocular motility data, the unit of analysis would be the individual eye. If participants were randomly allocated to treatment but only one eye per person was reported then there would be no unit-of-analysis issues. In these cases, we planned to document how the eye was selected. If participants were randomly allocated to treatment but both eyes were included and reported, we planned to analyse them as 'clustered data' (i.e. with adjustments for withinperson correlation). We planned to contact the trial investigators for further information in order to do this. The planned unit of analysis for quality of life was the participant. 


\section{Dealing with missing data}

If there were missing data in the included studies, we planned to contact the authors to obtain this information. If individual participant data were available from the authors, we planned to perform imputation using the multiple imputation by chained equations (MICE) approach (Resche-Rigon 2016). If standard deviations were missing, we planned to attempt to calculate them from the reported statistics (e.g. Cl, t statistics) (Higgins 2011a). We planned to perform sensitivity analyses by comparing the results with and without imputed data to assess the impact of imputation.

\section{Assessment of heterogeneity}

We planned to examine heterogeneity by examining study characteristics and forest plots of the results. We planned to use the 12 statistic to assess the proportion of the variance in the plot or analysis that reflects variation in true effects. We planned to interpret an 12 value greater than $50 \%$ as substantial heterogeneity.

\section{Assessment of reporting biases}

We planned to search PubMed, other major reference databases and the internet for a protocol for each included study. If a protocol was available, then we planned to compare outcomes mentioned in the protocol and in the published report. If there was no protocol, then we planned to compare the outcomes listed in the methods section of each article with those for which results were reported. We planned to seek further information from the authors of the study reports. We planned to use funnel plots to assess the evidence of publication bias if at least 10 suitable studies were available. If there were fewer than 10 studies, the funnel plot would not be appropriate due to the loss of power.

\section{Data synthesis}

If there was substantial clinical or statistical heterogeneity ( 12 greater than $50 \%$ ) we planned not to combine study results and instead would have presented an estimate of effect and associated $95 \% \mathrm{Cl}$ for each individual trial. If there was little variation between trials, we planned to combine the results in a meta-analysis using a fixed-effect model. If multi-arm studies were included, we planned to combine groups to create a single pair-wise comparison. We planned to use the formulae in Chapter 7 of the Cochrane Handbook for Systematic Reviews of Intervention to combine numbers into a single sample size, mean and standard deviation for each intervention group (Higgins 2011b).

\section{Subgroup analysis and investigation of heterogeneity}

We intended to stratify our findings by treatment dosage as a potential effect modifier. We planned to consider high $(8 \mathrm{mg} / \mathrm{kg})$ and low $(4 \mathrm{mg} / \mathrm{kg})$ dosage for subgroup analysis.

\section{Sensitivity analysis}

We planned to conduct sensitivity analyses to determine the impact of the exclusion of studies with lower methodological quality and industry-funded studies. Studies with low methodological quality were defined as the ones with high risk of bias in one or more domain in Cochrane risk of bias assessment.

\section{'Summary of findings' table}

See Table 1 and Table 2 for further details. Two review authors independently planned to grade the certainty of the evidence for each outcome using the GRADE approach, taking into account the size, consistency and precision of the effects, indirectness of the evidence and potential role of publication bias.(GRADEpro GDT).

\section{RES U LTS}

\section{Description of studies}

\section{Results of the search}

The electronic searches yielded 836 records (Figure 1). After removal of 120 duplicates, the Cochrane Information Specialist (CIS) screened the remaining 716 records and removed 686 records that were clearly not relevant to the scope of the review. We screened the remaining 30 records and obtained the full-text reports of three records for further assessment. We excluded two studies (see Characteristics of excluded studies for details). We found one ongoing study that met the inclusion criteria and this will be assessed for inclusion in the review when data become available (NCT01297699). 
Figure 1. Study flow diagram.

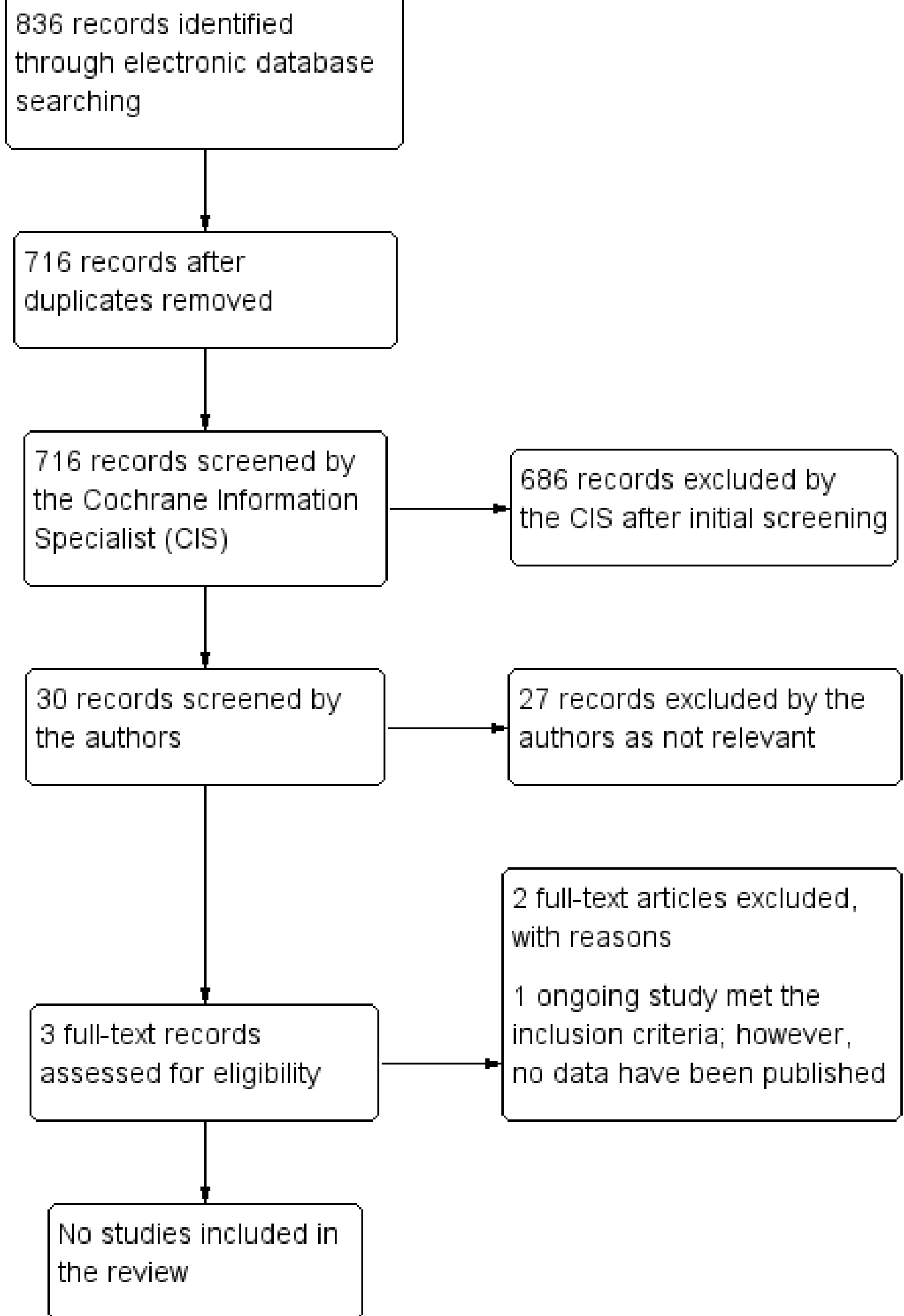




\section{Included studies}

No studies met our inclusion criteria.

\section{Excluded studies}

We excluded two studies after reviewing the full-text as they did not meet the inclusion criteria for this review (Perez-Moreiras 20014; Sy 2017). Details can be found in the Characteristics of excluded studies table.

\section{Ongoing studies}

We found one ongoing study that met the inclusion criteria in the clinical trials registry and contacted the authors, but the study results are not available yet (NCT01297699; see Characteristics of ongoing studies table).

\section{Risk of bias in included studies}

We found no published studies that met the inclusion criteria.

\section{Effects of interventions}

We found no published studies that met the inclusion criteria.

\section{DISCUSSION}

\section{Summary of main results}

Currently there are no published RCTs on tocilizumab for TED. There is one ongoing study that met the inclusion criteria but its results have not been published (NCT01297699).

\section{Overall completeness and applicability of evidence}

Not applicable.

\section{Quality of the evidence}

We identified no published trials for inclusion in this review. There is only one ongoing study that met the inclusion criteria, but its results have not been published yet.

\section{Potential biases in the review process}

We may not be aware of individuals or organisations who have conducted or may be conducting relevant RCTs. Although we identified one ongoing trial, but it is possible that relevant RCTs have not been identified.

\section{Agreements and disagreements with other studies or reviews}

We are unaware of any other reviews that have reported the effectiveness of tocilizumab for TED.

\section{AUTHORS' CONCLUSIONS}

\section{Implications for practice}

Currently there are no published randomised controlled trials (RCTs) of the effectiveness of tocilizumab for the management of thyroid eye disease. Therefore, clinicians do not have strong evidence for the use of tocilizumab in people with thyroid eye disease. There is one ongoing RCT. The result of this study should be assessed when it becomes available.

\section{Implications for research}

Currently there are no clinical trials providing evidence of the effectiveness and harms of tocilizumab in thyroid eye disease. Further research should be conducted in the form of RCTs to assess the effectiveness and harms of tocilizumab in thyroid eye disease. Thyroid eye disease is a sight threatening and disfiguring disease that is in need of a new effective treatment with better safety profile. A well-designed RCT to assess the use of tocilizumab in moderate to severe thyroid eye disease will help determine whether it could be routinely employed in treatment of thyroid eye disease. The outcomes should be addressed in a range of 6 to 12 months and include reduction of activity score and proptosis, improvement in extraocular movement and quality-of-life score and, reduced risk of optic neuropathy development.

\section{ACKNOWLEDGEMENTS}

The Cochrane Eyes and Vision has created and will execute the electronic search strategies. We would like to thank Faye Wellington and Jennifer Evans for their comments on the protocol and review, and Anupa Shah and the editorial team for helping with registration and preparation of the protocol and review. 


\section{RE F E R E N C E S}

\section{References to studies excluded from this review}

Perez-Moreiras 20014 \{published data only\}

Perez-Moreiras JV, Alvarez-Lopez A, Gomez EC. Treatment of active corticosteroid resistant graves' orbitopathy. Ophthalmic Plastic and Reconstructive Surgery 2014;30(2):162-7.

\section{Sy 2017 \{published data only\}}

Sy A, Eliasieh K, Silkiss RZ. Clinical response to Tocilizumab in severe thyroid eye disease. Ophthalmic Plastic and Reconstructive Surgery 2017;33(3):e55-7.

\section{References to ongoing studies}

NCT01297699 \{unpublished data only\}

NCT01297699. Tocilizumab treatment in Graves ophthalmopathy (Graves orbitopathy or thyroid eye disease) (GRC). clinicaltrials.gov/ct2/show/NCT01297699 Date first received: 17 February 2011.

\section{Additional references}

\section{Anvari 2010}

Anvari M, Khalizadeh O, Esteghamati A, Momen-Hervai F, Mahmoudi M, Esfahani SA, et al. Graves' disease and gene polymorphism of TNF- $\alpha$, IL-2, IL-6, IL-12, and IFN- $\gamma$. Endocrine 2010;37(2):344-8.

\section{Bahn 1993}

Bahn RS, Heufelder AE. Pathogenesis of Graves' ophthalmopathy. New England Journal of Medicine 1993;329(20):1468-75.

\section{Bahn 2010}

Bahn RS. Graves' ophthalmopathy. New England Journal of Medicine 2010;362(8):726-38.

\section{Bahn 2011}

Bahn RS, Burch HB, Cooper DS, Garber JR, Greenlee MC, Klein I, et al. Hyperthyroidism and other causes of thyrotoxicosis: management guidelines of the American Thyroid Association and American Association of Clinical Endocrinologists. Endocrine Practice 2011;17(3):456-520.

\section{Barrio-Barrio 2015}

Barrio-Barrio J, Sabater AL, Bonet-Farriol E, Velázquez-Villoria Á, Galofré JC. Graves' ophthalmopathy: VISA versus EUGOGO classification, assessment, and management. Journal of Ophthalmology 2015;2015:249125. [DOI: 10.1155/2015/249125]

\section{Bartalena 2002}

Bartalena L, Marcocci C, Tanda M, Rocchi R, Mazzi B, Barbesino G, et al. Orbital radiotherapy for Graves' ophthalmopathy. Thyroid 2002;12(3):245-50.

\section{Bartalena 2008}

Bartalena L, Baldeschi L, Dickinson AJ, Eckstein A, KendallTaylor P, Marocci C, et al. Consensus statement of the European group on Graves' orbitopathy (EUGOGO) on management of Graves' orbitopathy. Thyroid 2008;18(3):333-46.

\section{Bartalena 2016}

Bartalena L, Baldeschi L, Boboridis K, Eckstein A, Kahaly GJ, Marcocci C, et al. The 2016 European Thyroid Association/ European Group on Graves' Orbitopathy guidelines for the management of Graves' orbitopathy. European Thyroid Journal 2016;5(1):9-26.

\section{Bartley 1995}

Bartley GB, Fatourechi V, Kadrmas EF, Jacobsen SJ, Ilstrup DM, Garrity JA, et al. The incidence of Graves' ophthalmopathy in Olmsted County, Minnesota. American Journal of Ophthalmology 1995;120(4):511-7.

\section{Boboridis 2011}

Boboridis KG, Bunce C. Surgical orbital decompression for thyroid eye disease. Cochrane Database of Systematic Reviews 2011, Issue 12. [DOI: 10.1002/14651858.CD007630.pub2]

\section{Boboridis 2015}

Boboridis K, Uddin J, Mikropoulos D, Bunce C, Mangouritsas G, Voudouragkaki I, et al. Critical appraisal on orbital decompression for thyroid eye disease: a systematic review and literature search. Advances in Therapy 2015;32(7):595-611.

\section{Burch 1993}

Burch HB, Wartofsky L. Graves' ophthalmopathy: current concepts regarding pathogenesis and management. Endocrine Reviews 1993;14(6):747-93.

\section{Covidence [Computer program]}

Veritas Health Innovation. Covidence. Version accessed prior to 17 October 2018. Melbourne: Veritas Health Innovation.

\section{Eckstein 2009}

Eckstein AK, Johnson KT, Thanos M, Esser J, Ludgate M. Current insights into the pathogenesis of Graves' orbitopathy. Hormone and Metabolic Research 2009;41(6):456-64.

\section{EUGOGO 2006}

European Group on Graves' Orbitopathy (EUGOGO), Wiersinga WM, Perros P, Kahaly GJ, Mourits MP, Baldeschi L, et al. Clinical assessment of patients with Graves' orbitopathy: the European Group on Graves' Orbitopathy recommendations to generalists, specialists and clinical researchers. European Journal of Endocrinology 2006;155(3):387-89.

\section{Ezra 2012}

Ezra DG, Krell, J, Rose GE, Basily M, Stebbing J, Castellano L. Transcriptome-level microarray expression profiling implicates IGF-1 and Wnt signalling dysregulation in the pathogenesis of thyroid-associated orbitopathy. Journal of Clinical Pathology 2012;65(7):608-13.

\section{Firestein 2003}

Firestein GS. Evolving concepts of rheumatoid arthritis. Nature 2003;423(6937):356-61. 


\section{GRADEpro GDT [Computer program]}

MCMaster University (developed by Evidence Prime). GRADEpro GDT. Version accessed prior to 31 July 2018. Hamilton (ON): McMaster University (developed by Evidence Prime), 2015.

\section{Han 2006}

Han R, Smith TJ. T helper type 1 and type 2 cytokines exert divergent influence on the induction of prostaglandin E2 and hyaluronan synthesis by interleukin-1beta in orbital fibroblasts: implications for the pathogenesis of thyroid-associated ophthalmopathy. Endocrinology 2006;147(1):13-9.

\section{Higgins 2011a}

Higgins JP, Deeks JJ, Altman DG. Chapter 16: Special topics in statistics. In: Higgins JPT, Green S, editors. Cochrane Handbook for Systematic Reviews of Interventions. Version 5.1.0 (updated March 2011). The Cochrane Collaboration, 2011. Available from handbook.cochrane.org.

\section{Higgins 2011b}

Higgins JP, Deeks JJ. Chapter 7: Selecting studies and collecting data. In: Higgins JPT, Green S, editor(s), Cochrane Handbook for Systematic Reviews of Interventions Version 5.1.0 (updated March 2011). The Cochrane Collaboration, 2011. Available from handbook.cochrane.org.

\section{Higgins 2017}

Higgins JP, Altman DG, Sterne JA. Chapter 8: Assessing risk of bias in included studies. In: Higgins JP, Churchill R, Chandler J, Cumpston MS, editor(s), Cochrane Handbook for Systematic Reviews of Interventions version 5.2.0 (updated June 2017). Cochrane, 2017. Available from www.training.cochrane.org/ handbook.

\section{Hiromatsu 2000}

Hiromatsu Y, Yang D, Bednarczuk T, Miyake I, Nonaka Y, Inoue Y. Cytokine profiles in eye muscle tissue and orbital fat tissue from patients with thyroid-associated ophthalmopathy. Journal of Clinical Endocrinology and Metabolism 2000;85(3):1194-9.

\section{Jyonouchi 2001}

Jyonouchi SC, Valyasevi RW, Harteneck DA, Dutton CM, Bahn RS. Interleukin-6 stimulates thyrotropin receptor expression in human orbital preadipocyte fibroblasts from patients with Graves' ophthalmopathy. Thyroid 2001;11(10):929-34.

\section{Kahaly 2005}

Kahaly GJ, Petrak F, Hardt J, Pitz S, Egle UT. Psychosocial morbidity of Graves' orbitopathy. Clinical Endocrinology 2005;63(4):395-402.

\section{Kaneko 2013}

Kaneko A. Tocilizumab in rheumatoid arthritis: efficacy, safety and its place in therapy. Therapeutic Advances in Chronic Disease 2013;4(1):14-21.

\section{Kingdom 2015}

Kingdom TT, Davies BW, Durairaj VD. Orbital decompression for the management of thyroid eye disease: an analysis of outcomes and complications. Laryngoscope 2015;125(9):2034-40.

\section{Lehmann 2008}

Lehmann GM, Feldon SE, Smith TJ, Phipps RP. Immune mechanisms is thyroid eye disease. Thyroid 2008;18(9):959-65.

\section{Li 2016}

Li HX, Xiang N, Hu WK, Jiao XL. Relation between therapy options for Graves' disease and the course of Graves' ophthalmopathy: a systematic review and meta-analysis. Journal of Endocrinological Investigation 2016;39(11):1225-33.

\section{Minakaran 2013}

Minakaran N, Ezra D. Rituximab for thyroid-associated ophthalmopathy. Cochrane Database of Systematic Reviews 2013, Issue 5. [DOI: 10.1002/14651858.CD009226.pub2]

\section{Mourits 1989}

Mourits MP, Koornneef L, Wiersinga WM, Prummel MF, Berghout A, Van der Gaag R. Clinical criteria for the assessment of disease activity in Graves' ophthalmopathy: a novel approach. British Journal of Ophthalmology 1989;73(8):639-44.

\section{Mourits 1997}

Mourits MP, Prummel MF, Wiersinga WM, Koornneef L. Clinical activity score as a guide in the management of patients with Graves' ophthalmopathy. Clinical Endocrinology 1997;47(1):9-14.

\section{Natt 1997}

Natt N, Bahn RS. Cytokines in the evolution of Graves' ophthalmopathy. Autoimmunity 1997;26(2):129-36.

\section{Perez-Moreiras 2014}

Perez-Moreiras J, Alvarez-Lopez A, Gomez E. Treatment of active corticosteroid-resistant Graves' orbitopathy. Ophthalmic Plastic and Reconstructive Surgery 2014;30(2):162-7.

\section{Prabhakar 2003}

Prabhakar BS, Bahn RS, Smith TJ. Current perspective on the pathogenesis of Graves' disease and ophthalmopathy. Endocrine Reviews 2003;24(6):802-35.

\section{Rajendram 2008}

Rajendram R, Lee RW, Potts MJ, Rose GE, Jain R, Olver JM, et al. Protocol for the combined immunosuppression \& radiotherapy in thyroid eye disease (CIRTED) trial: a multi-centre, doublemasked, factorial randomised controlled trial. Trials 2008;9:6. [DOI: 10.1186/1745-6215-9-6]

\section{Rajendram 2012}

Rajendram R, Bunce C, Lee RW, Morley AM. Orbital radiotherapy for adult thyroid eye disease. Cochrane Database of Systematic Reviews 2012, Issue 7. [DOI: 10.1002/14651858.CD007114.pub2]

\section{Resche-Rigon 2016}

Resche-Rigon M, White IR. Multiple imputation by chained equations for systematically and sporadically missing multilevel data. Statistical Methods in Medical Research 2016;27(6):1634-49. 


\section{Review Manager 2014 [Computer program]}

Nordic Cochrane Centre, The Cochrane Collaboration. Review Manager 5 (RevMan 5). Version 5.3. Copenhagen: Nordic Cochrane Centre, The Cochrane Collaboration, 2014.

\section{Rose-John 2007}

Rose-John S, Waetzig GH, Scheller J, Grötzinger J, Seegert D. The IL-6/sIL-6R complex as a novel target for therapeutic approaches. Expert Opinion on Therapeutic Targets 2007;11(5):613-24.

\section{Slowik 2012}

Slowik M, Urbaniak-Kujda D, Bohdanowicz-Pawlak A, KapelkoSlowik K, Dybko J, Wolowiec D, et al. CD8+CD28-lymphocytes in peripheral blood and serum concentrations of soluble interleukin 6 receptor are increased in patients with Graves' orbitopathy and correlate with disease activity. Endocrine Research 2012;37(2):89-95.

\section{Smith 1997}

Smith RS, Smith TJ, Blieden TM, Phipps RP. Fibroblasts as sentinel cells. Synthesis of chemokines and regulation of inflammation. American Journal of Pathology 1997;151(2):317-22.

\section{Smolen 2003}

Smolen JS, Steiner G. Therapeutic strategies for rheumatoid arthritis. Nature Reviews. Drug Discovery 2003;2(6):473-88.

\section{Sorisky 1996}

Sorisky A, Pardasani D, Gagnon A, Smith TJ. Evidence of adipocyte differentiation in human orbital fibroblasts in primary culture. Journal of Clinical Endocrinology and Metabolism 1996;81(9):3428-31.

\section{Stan 2012}

Stan MN, Garrity JA, Bahn RS. The evaluation and treatment of graves ophthalmopathy. Medical Clinics of North America 2012;96(2):311-28.

\section{CHARACTERISTICS OF STUDIES}

\section{Characteristics of excluded studies [ordered by study ID]}

\section{Thornton 2007}

Thornton J, Kelly SP, Harrison RA, Edwards R. Cigarette smoking and thyroid eye disease: a systematic review. Eye 2007;21(9):1135-45.

\section{Weetman 2000}

Weetman AP. Graves' disease. New England Journal of Medicine 2000;343(17):1236-48.

\section{Werner 1969}

Werner SC. Classification of the eye changes of Graves' disease. American Journal of Ophthalmology 1969;68:646-8.

\section{Werner 1977}

Werner SC. Modification of the classification of the eye changes of Graves' disease. American Journal of Ophthalmology 1977;83(5):725-7.

\section{Wickwar 2015}

Wickwar S, McBain H, Ezra DG, Hirani SP, Rose GE, Newman SP. The psychosocial and clinical outcomes of orbital decompression surgery for thyroid eye disease and predictors of change in quality of life. Ophthalmology 2015;122(12):2568-76.

\section{Wiersinga 2001}

Wiersinga WM, Prummel MF. Pathogenesis of Graves' ophthalmopathy - current understanding. Journal of Clinical Endocrinology and Metabolism 2001;86(2):501-3.

\section{Xing 2015}

Xing L, Ye L, Zhu W, Shen L, Huang F, Jiao Q, et al. Smoking was associated with poor response to intravenous steroids therapy in Graves' ophthalmopathy. British Journal of Ophthalmology 2015;99(12):1686-91.

\section{Yang 2011}

Yang D, Gonzalez M, Durairaj V. Medical management of thyroid eye disease. Saudi Journal of Ophthalmology 2011;25(1):3-13.

\begin{tabular}{ll}
\hline Study & Reason for exclusion \\
\hline Perez-Moreiras 20014 & $\begin{array}{l}\text { Non-randomised prospective open-labelled interventional case series investigated tocilizumab for } \\
\text { people with glucocorticoid refractory thyroid associated orbitopathy. }\end{array}$ \\
\hline Sy 2017 & Case study \\
\hline
\end{tabular}

Characteristics of ongoing studies [ordered by study ID]

NCT01297699

Trial name or title

Tocilizumab treatment in Graves' ophthalmopathy (Graves' orbitopathy or thyroid eye disease) 
NCT01297699 (Continued)

Methods
Phase III, parallel group, randomised, placebo-controlled, double-blind, multicentre study to evaluate the efficacy and safety of tocilizumab administration in people with moderate-to-severe or sight-threatening GO, that had not responded adequately to treatment with intravenous corticoid pulses.
Participants

\section{Principal inclusion criteria}

Men or women aged $18-75$ years

Diagnosed with GO with CAS $\geq 4$ and an index of severity, according EUGOGO guidelines, moderate-to-severe or sight-threatening $\mathrm{GO}$, after receiving corticosteroid pulse treatment due to:

- poor response to intravenous corticosteroid pulses or

- recurrence of the $\mathrm{GO}$, after treatment with intravenous corticosteroids.

Exclusion criteria

- Orbital decompression surgery needed immediately

- Active smoker

- People who could need treatment with radioactive iodine or thyroidectomy during the study

- Pregnant women or women planning to become pregnant during the study

- History of chronic recurrent or active infection

- History of intestinal ulceration or diverticulitis

- People with a history of chronic liver disease or liver disorders: alanine aminotransferase and aspartate aminotransferase above 5 times upper limit of normal

- History of HIV, hepatitis C or hepatitis B positive

- Neutrophil count $<0.5 \times 10^{9} / \mathrm{L}$ or a platelet count $<50 \times 10^{3} / \mu \mathrm{L}$

- Simultaneous use or contraindications to the use of immunosuppressive agents

- Treatment with another investigational drug within 4 weeks of selection or 5 half-lives of study drug

- Clinically significant cardiovascular or cerebrovascular disease

- Uncontrolled diabetes mellitus

- Use of corticosteroids during 4 weeks before to inclusion period

- History of reactions or anaphylactic allergic severe human monoclonal antibodies, humanised or murine

- Uncontrolled pathologies, whose exacerbations were treated with corticosteroids
- Intervention: tocilizumab (RoActemra)

Single intravenous infusion of tocilizumab $(8 \mathrm{mg} / \mathrm{kg})$; every 4 weeks for 16 weeks

- Comparator: sterile $0.9 \%$ sodium chloride

Single intravenous drip infusion of sterile $0.9 \%$ sodium chloride, every 4 weeks for 16 weeks
Primary outcome:

- Drug efficacy established as a decrease in CAS by $\geq 2$ points in a scale of 10 . Measured before treatment (week 0), after treatment (week 16) and after end of follow-up (week 40).

Secondary outcomes:

- Clinical response of participants who responded to treatment with tocilizumab. Analysed before treatment (week 0), after treatment (week 16) and once to follow-up (week 40).

- Quality of life associated with tocilizumab treatment, using SF-36. Analysed before treatment (week 0), after treatment (week 16) and once to follow-up (week 40).

- Time to recurrence during follow-up period. Measured on a 1-week time scale by the physician during participant follow-up visits. 
NCT01297699 (Continued)

- Adverse events

\begin{tabular}{ll}
\hline Starting date & March 2012 \\
\hline Contact information & Juan.Jesus.Gomez-Reino.Carnota@sergas.es \\
\hline Notes & No study results available \\
& Date study completed: December 2015
\end{tabular}

CAS: Clinical Activity Score; EUGOGO: European Group On Graves' Orbitopathy; GO: Graves' ophthalmopathy; SF-36: 36-item Short Form.

ADDITIONAL TABLES

Table 1. Type of intervention: intravenous tocilizumab treatment versus standard treatment. Type of studies: randomised controlled trials

\begin{tabular}{|c|c|c|c|c|c|}
\hline Outcomes & Measure & $\begin{array}{l}\text { Relative ef- } \\
\text { fect }\end{array}$ & $\begin{array}{l}\text { Number of } \\
\text { participants } \\
\text { (studies) }\end{array}$ & $\begin{array}{l}\text { Quality of ev- } \\
\text { idence } \\
\text { (GRADEa) }\end{array}$ & Comments \\
\hline $\begin{array}{l}\text { Change in TED as } \\
\text { defined by investi- } \\
\text { gators }\end{array}$ & $\begin{array}{l}\text { Measured in CAS/EUGOGO/NOSPECS/ } \\
\text { VISA classification at } 12 \text { months (range } \\
6-18 \text { months) post treatment }\end{array}$ & - & - & - & - \\
\hline $\begin{array}{l}\text { Change in propto- } \\
\text { sis }\end{array}$ & $\begin{array}{l}\text { Measured in millimetres at } 12 \text { months } \\
\text { (range } 6-18 \text { months) post treatment }\end{array}$ & - & - & - & - \\
\hline $\begin{array}{l}\text { Change in extraoc- } \\
\text { ular motility }\end{array}$ & $\begin{array}{l}\text { Measured in degrees at } 12 \text { months } \\
\text { (range } 6-18 \text { months) post treatment }\end{array}$ & - & - & - & - \\
\hline $\begin{array}{l}\text { Number of relaps- } \\
\text { es }\end{array}$ & $\begin{array}{l}\text { Per participant at } 12 \text { months (range 6- } \\
18 \text { months) post treatment }\end{array}$ & - & - & - & - \\
\hline $\begin{array}{l}\text { Development of } \\
\text { optic neuropathy }\end{array}$ & $\begin{array}{l}\text { As defined by the trial investigators at } \\
12 \text { months (range } 6-18 \text { months) post } \\
\text { treatment }\end{array}$ & - & - & - & - \\
\hline $\begin{array}{l}\text { Change in quali- } \\
\text { ty-of-life score }\end{array}$ & $\begin{array}{l}\text { GO-QOL score or EQ-5D score at } 12 \\
\text { months (range } 6-18 \text { months) post treat- } \\
\text { ment }\end{array}$ & - & - & - & $\begin{array}{l}\text { MCID = } 6 \\
\text { points }\end{array}$ \\
\hline Adverse effects & $\begin{array}{l}\text { Any adverse effect that is reported at } 12 \\
\text { months (range } 6-18 \text { months) post treat- } \\
\text { ment }\end{array}$ & - & - & - & - \\
\hline
\end{tabular}

aThe GRADE approach defines the quality of a body of evidence as the extent to which one can be confident that an estimate of effect or association is close to the quantity of specific interest. Certainty of a body of evidence involves consideration of within-study risk of bias (methodological quality), directness of evidence, heterogeneity, precision of effect estimates and risk of publication bias.

CAS: Clinical Activity Score; EQ-5D: European Quality of life questionnaire; EUGOGO: European Group On Graves' Orbitopathy; GO-QOL: Graves' Orbitopathy Quality of Life questionnaire; MCID: minimal clinically important difference; NOSPECS: No symptoms or signs, Only signs, Soft tissue involvement, Proptosis, Extraocular muscle involvement, Corneal involvement and Sight loss. It is graded as 0, a, b or c; TED: thyroid eye disease; VISA: Vision, Inflammation, Strabismus, and Appearance classification.

We planned to express the treatment effect for each continuous outcome as a mean difference with $95 \%$ confidence interval (CI). Where continuous outcomes were measured using different scales, we planned to express the treatment effect as a standardised mean difference with $95 \% \mathrm{Cl}$. 
Table 2. Type of intervention: intravenous tocilizumab treatment versus placebo. Type of studies: randomised controlled trials

\begin{tabular}{|c|c|c|c|c|c|}
\hline Outcomes & Measure & $\begin{array}{l}\text { Relative } \\
\text { effect }\end{array}$ & $\begin{array}{l}\text { Number of } \\
\text { participants } \\
\text { (studies) }\end{array}$ & $\begin{array}{l}\text { Quality of ev- } \\
\text { idence } \\
\left(\text { GRADE}^{a}\right)\end{array}$ & Comments \\
\hline $\begin{array}{l}\text { Change in TED as } \\
\text { defined by investi- } \\
\text { gators }\end{array}$ & $\begin{array}{l}\text { Measured in CAS/EUGOGO/NOSPECS/ } \\
\text { VISA classification at } 12 \text { months (range } \\
6-18 \text { months) post treatment }\end{array}$ & - & - & - & - \\
\hline $\begin{array}{l}\text { Change in propto- } \\
\text { sis }\end{array}$ & $\begin{array}{l}\text { Measured in millimetres at } 12 \text { months } \\
\text { (range 6-18 months) post treatment }\end{array}$ & - & - & - & - \\
\hline $\begin{array}{l}\text { Change in extraoc- } \\
\text { ular motility }\end{array}$ & $\begin{array}{l}\text { Measured in degrees at } 12 \text { months } \\
\text { (range 6-18 months) post treatment }\end{array}$ & - & - & - & - \\
\hline $\begin{array}{l}\text { Number of relaps- } \\
\text { es }\end{array}$ & $\begin{array}{l}\text { Per participant at } 12 \text { months (range } 6- \\
18 \text { months) post treatment }\end{array}$ & - & - & - & - \\
\hline $\begin{array}{l}\text { Development of } \\
\text { optic neuropathy }\end{array}$ & $\begin{array}{l}\text { As defined by the trial investigators at } \\
12 \text { months (range } 6-18 \text { months) post } \\
\text { treatment }\end{array}$ & - & - & - & - \\
\hline $\begin{array}{l}\text { Change in quali- } \\
\text { ty-of-life score }\end{array}$ & $\begin{array}{l}\text { GO-QOL score or EQ-5D score at } 12 \\
\text { months (range } 6-18 \text { months) post treat- } \\
\text { ment }\end{array}$ & - & - & - & $\begin{array}{l}\text { MCID = } 6 \\
\text { points }\end{array}$ \\
\hline Adverse effects & $\begin{array}{l}\text { Any adverse effect that is reported at } 12 \\
\text { months (range } 6-18 \text { months) post treat- } \\
\text { ment }\end{array}$ & - & - & - & - \\
\hline
\end{tabular}

aThe GRADE approach defines the quality of a body of evidence as the extent to which one can be confident that an estimate of effect or association is close to the quantity of specific interest. Certainty of a body of evidence involves consideration of within-study risk of bias (methodological quality), directness of evidence, heterogeneity, precision of effect estimates and risk of publication bias.

CAS: Clinical Activity Score; EQ-5D: European Quality of life questionnaire; EUGOGO: European Group On Graves' Orbitopathy; GO-QOL: Graves' Orbitopathy Quality of Life questionnaire; MCID: minimal clinically important difference; NOSPECS: No symptoms or signs, Only signs, Soft tissue involvement, Proptosis, Extraocular muscle involvement, Corneal involvement and Sight loss. It is graded as 0, a, b or c; TED: thyroid eye disease; VISA: Vision, Inflammation, Strabismus, and Appearance classification.

We planned to express the treatment effect for each continuous outcome as a mean difference with $95 \%$ confidence interval (CI). Where continuous outcomes were measured using different scales, we planned to express the treatment effect as a standardised mean difference with $95 \% \mathrm{Cl}$.

\section{AP PE N DICES}

\section{Appendix 1. CENTRAL search strategy}

\#1 MeSH descriptor: [Graves Disease] explode all trees \#2 MeSH descriptor: [Graves Ophthalmopathy] explode all trees \#3 grave* near ophthalm* \#4 grave* near orbitopath* \#5 (thyroid*) near (ophthalm* or eye $^{\star}$ )

\#6 TED or TAO

$\# 7$ basedow ${ }^{\star}$ next disease ${ }^{*}$

\#8 \#1 or \#2 or \#3 or \#4 or \#5 or \#6 or \#7

\#9 MeSH descriptor: [Antibodies, Monoclonal] explode all trees \#10 MeSH descriptor: [Interleukin-6] this term only 
\#11 MeSH descriptor: [Receptors, Interleukin-6] this term only

\#12 (tocilizumab or TCZ)

\#13 (atlizumab or actemra or roactemra)

\#14 (anti IL 6 next receptor)

\#15 (anti interleukin 6 next receptor)

\#16 monoclonal near/4 antibod*

\#17 (lymphocyte* or cell ${ }^{\star}$ ) near/4 agent ${ }^{\star}$

$\# 18 \# 9$ or \#10 or \#11 or \#12 or \#13 or \#14 or \#15 or \#16 or \#17

$\# 19 \# 8$ and \#18

\section{Appendix 2. MEDLINE Ovid search strategy}

1. randomized controlled trial.pt.

2. (randomized or randomised).ab,ti.

3. placebo.ab,ti.

4. dt.fs.

5. randomly.ab,ti.

6. trial.ab,ti.

7. groups.ab,ti.

8. or/1-7

9. exp animals/

10. exp humans/

11.9 not (9 and 10$)$

12. 8 not 11

13. exp graves disease/

14. exp graves ophthalmopathy/

15. (grave\$ adj3 ophthalm\$).tw.

16. (grave $\$$ adj3 orbitopath\$).tw.

17. ((ophthalm\$ or orbitopath\$ or eye\$) adj3 thyroid\$).tw.

18. (TED or TAO).tw.

19. (basedow $\$$ adj3 disease $\$$ ).tw.

20. or/13-19

21. exp antibodies, monoclonal/

22. Interleukin-6/

23. Receptors, Interleukin-6/

24. (tocilizumab or TCZ).tw.

25. (atlizumab or actemra or roactemra).tw.

26. ((anti IL 6 or anti interleukin 6) adj1 receptor).tw.

27. (monoclonal adj4 antibod\$).tw.

28. ((lymphocyte\$ or cell\$) adj4 agent\$).tw.

29. or/21-28

30. 12 and 20 and 29

\section{Appendix 3. Embase Ovid search strategy}

1. exp randomized controlled trial/

2. exp randomization/

3. exp double blind procedure/

4. exp single blind procedure/

5. random\$.tw.

6. or/1-5

7. (animal or animal experiment).sh.

8. human.sh.

9. 7 and 8

10.7 not 9

11.6 not 10

12. exp clinical trial/

13. (clin\$ adj3 trial\$).tw.

14. ((singl\$ or doubl\$ or trebl\$ or tripl\$) adj3 (blind\$ or mask\$)).tw.

15. exp placebo/

16. placebo\$.tw.

17. random\$.tw.

18. exp experimental design/

Tocilizumab for thyroid eye disease (Review)

Copyright (c) 2018 The Cochrane Collaboration. Published by John Wiley \& Sons, Ltd. 
19. exp crossover procedure/

20. exp control group/

21. exp latin square design/

22. or $/ 12-21$

23. 22 not 10

24. 23 not 11

25. exp comparative study/

26. exp evaluation/

27. exp prospective study/

28. (control\$ or prospectiv\$ or volunteer\$).tw.

29. or $/ 25-28$

30.29 not 10

31.30 not (11 or 23 )

32. 11 or 24 or 31

33. exp graves disease/

34. exp endocrine ophthalmopathy/

35. (grave $\$$ adj3 ophthalm\$).tw.

36. (grave $\$$ adj3 orbitopath\$).tw.

37. ((ophthalm\$ or orbitopath\$ or eye\$) adj3 thyroid\$).tw.

38. (TED or TAO).tw.

39. (basedow\$ adj3 disease\$).tw.

40. or/33-39

41. exp monoclonal antibody/

42. interleukin $6 /$

43. interleukin 6 receptor/

44. (tocilizumab or TCZ).tw.

45. (atlizumab or actemra or roactemra).tw.

46. ((anti IL 6 or anti interleukin 6) adj1 receptor).tw.

47. (monoclonal adj4 antibod\$).tw.

48. ((lymphocyte\$ or cell\$) adj4 agent\$).tw.

49. or/41-48

50. 32 and 40 and 49

\section{Appendix 4. LILACS search strategy}

graves or thyroid and ophthalm\$ or orbit\$ or disease or TED or TAO and monoclonal antibod\$ or tocilizumab or interleukin-6 or IL-6

\section{Appendix 5. OpenGrey search strategy}

tocilizumab

\section{Appendix 6. ISRCTN search strategy}

(thyroid eye disease OR thyroid associated orbitopathy OR ophthalmopathy OR TED or TAO) AND Tocilizumab

\section{Appendix 7. ClinicalTrials.gov search strategy}

(Thyroid Eye Disease OR Thyroid Associated Orbitopathy OR Ophthalmopathy OR TED or TAO) AND tocilizumab

\section{Appendix 8. WHO ICTRP search strategy}

thyroid eye OR ophthalmopathy OR orbitopathy OR TAO OR TED = Condition AND tocilizumab = Intervention

\section{Appendix 9. EU Clinical Trials Register search strategy}

Thyroid AND tocilizumab

Appendix 10. Data on study characteristics

\section{Methods}

Tocilizumab for thyroid eye disease (Review) 
(Continued)

\section{Study design}

- Parallel group RCTi.e. people randomised to treatment

- Within-person RCTi.e. eyes randomised to treatment

- Cluster RCTi.e. communities randomised to treatment

- Cross-over RCT

- Other, specify
Exclusions after randomisation

Losses to follow up

Number ran-

domised/analysed

How were missing data handled? e.g. available case analysis, imputation methods

Reported power calculation $(\mathrm{Y} / \mathrm{N})$, if yes, sample size and power

Unusual study design/issues

\begin{tabular}{lll}
\hline Participants & - & - \\
\hline Country & - & Setting \\
\cline { 1 - 2 } $\begin{array}{lll}\text { Total number of partici- } \\
\text { pants }\end{array}$ & $\begin{array}{l}\text { This information should be collected for total study population recruited } \\
\text { into the study. If these data are reported only for the people who were } \\
\text { followed up only, please indicate }\end{array}$ & $\begin{array}{l}\text { Equivalence of baseline char- } \\
\text { acteristics }(\mathrm{Y} / \mathrm{N})\end{array}$
\end{tabular}

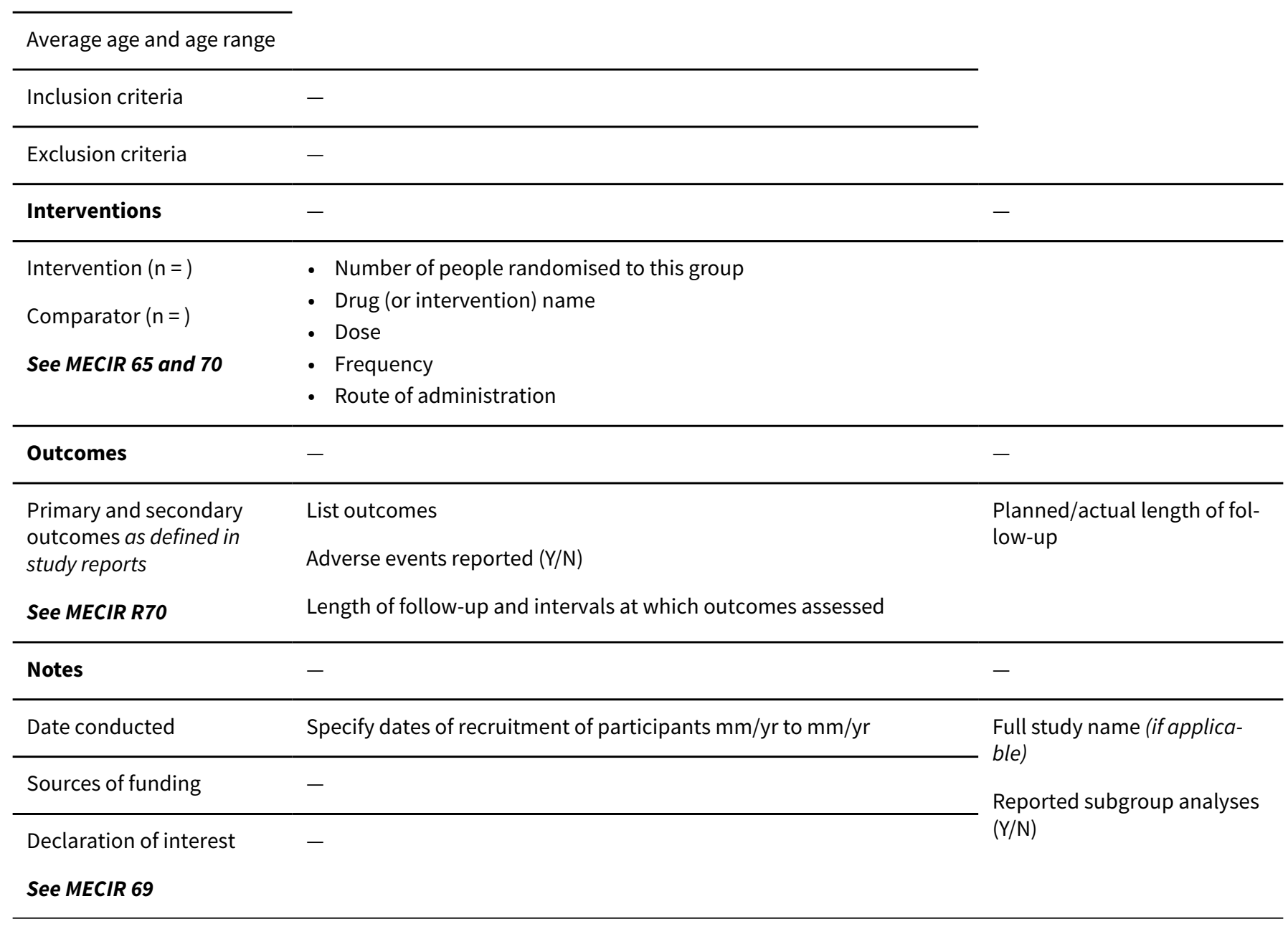




\section{CONTRIBUTIONS OF AUTHORS}

\section{Protocol}

Drafting the protocol: SHA, SK.

Drafting the final version of the protocol: DGE, MS.

\section{Review}

Drafting the review: SHA, SK.

Drafting the final version of the review: DGE, MS.

\section{DECLARATIONS OF INTEREST}

SHA: none known.

SK: none known.

MS: none known.

DGE: none known.

\section{SOURCES OF SUPPORT}

\section{Internal sources}

- No sources of support supplied

\section{External sources}

- National Institute for Health Research (NIHR), UK.

* Richard Wormald, Co-ordinating Editor for Cochrane Eyes and Vision (CEV) acknowledges financial support for his CEV research sessions from the Department of Health through the award made by the National Institute for Health Research to Moorfields Eye Hospital NHS Foundation Trust and UCL Institute of Ophthalmology for a Specialist Biomedical Research Centre for Ophthalmology.

* This review was supported by the NIHR, via Cochrane Infrastructure funding to the CEV UK editorial base.

The views and opinions expressed therein are those of the authors and do not necessarily reflect those of the Systematic Reviews Programme, NIHR, National Health Service or the Department of Health.

\section{INDEX TERMS}

\section{Medical Subject Headings (MeSH)}

Antibodies, Monoclonal, Humanized [ ${ }^{\star}$ therapeutic use]; Graves Ophthalmopathy [ ${ }^{\star}$ drug therapy] [immunology]; Interleukin-6 [*antagonists \& inhibitors]

\section{MeSH check words}

Humans 